\title{
Adhesives Industry Still on Track for Growth
}

With a production volume of 870,000 tonnes in 2011, the German adhesives industry has set a new record for the second year in a row and increased its share of the European market to more than $36 \%$. In 2012, the industry expects its overall turnover to grow organically by around $3.5 \%$ to approximately 3.4 billion euros. By the end of 2012, the industry will have produced more than 1.4 million tonnes of adhesives, sealants and cement-based construction products, together with almost one billion square metres of adhesive tape and film.

D emand for adhesives continues to increase. During a recent representative survey carried out by the German Adhesives Association (IVK), the 123 members of the association confirmed that they had good order books and were seeing a steady rise in sales in all the key market segments. Growth is particularly strong in the construction and construction-related industries and in exports.

There are currently no problems with the availability of raw materials. However, the adhesives industry is seeing no noticeable let-up in the pressure on prices. As the prices of key raw materials are currently determined by supply and demand, rather than by crude oil prices and speculation, the levels of price increases are relatively moderate. However, the costs of the majority of precursors for the manufacture of adhesives and the costs of energy and transport remain high.

The turnover figures produced by the German Federal Statistical Office (Destatis) show an increase in sales for the German adhesives industry of $4 \%$ in the first six months of 2012 and 4.9 $\%$ in the first seven months. Despite the modified economic forecasts and the high level of volatility in the economy, the German Adhesives Association is of the opinion that overall growth is likely to reach around $3.5 \%$, which would bring the industry's total turnover to 3.4 billion euros. Providing that there are no radical changes in general economic conditions, it is likely that growth of 3.5 \% can be expected again in 2013.

This means that the German adhesives industry is growing faster than the economy as a whole. This is the direct result of the practical, added-value solutions provided by the adhesives industry to accompany its customers' innovative technological developments.

New applications

Adhesives have proved their value in almost all areas of industry. Just a few examples of the products which can only be manufactured using innovative, high-performance adhesives include crash-resistant components in cars, biometric passports, mobile phones, tablet PCs, endoscopes and wind turbines.

"The huge variety of potential applications for adhesives, which range from

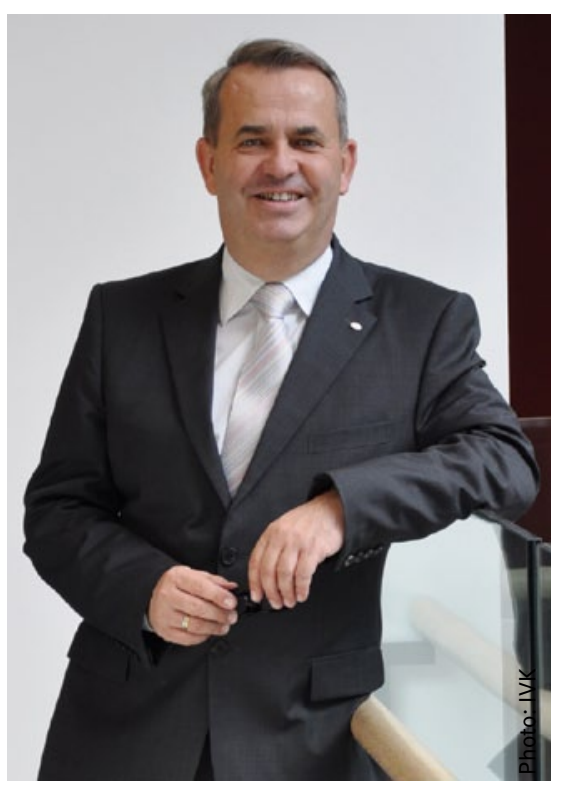

"The huge variety of potential applications for adhesives, which range from cars to dental crowns, opens up a large number of niche markets and technical opportunities. These applications also represent the core business of the 125 or so companies involved in the adhesives market in Germany," explains Dr. Boris Tasche, President of the German Adhesives Association (IVK) cars to dental crowns, opens up a large number of niche markets and technical opportunities. These applications also represent the core business of the 125 or so companies involved in the adhesives market in Germany," explains Dr. Boris Tasche, President of the German Adhesives Association.

In addition, developments and objectives in the field of regulatory and social policy, among other areas, are leading to new applications for adhesives. The current in-depth debate on sustainability represents a very welcome opportunity for the German adhesives industry to demonstrate its innovative ability and its portfolio of products and services.

For example, the goal of making homes more energy-efficient can only be achieved with the help of adhesives. This includes insulating heating and water pipes and installing external thermal insulation composite systems in facades and roofs, which require the use of adhesives and sealants.

Furthermore, the discussions on sustainability will inevitably lead to changes in industrial production processes. For example, suitable alternatives are needed to replace joining methods that use large amounts of energy, such as welding or soldering. The adhesives industry already has innovative high-performance adhesives available which make ideal replacements.

Last but not least, the key to manufacturing environmentally efficient products lies in lightweight structures and these can only be produced using specially developed adhesives.

For more information, please visit: www.klebstoffe.com 